\title{
Influence of the Microstructure of the Initial Material on the Zn Wires Prepared by Direct Extrusion with a Huge Extrusion Ratio
}

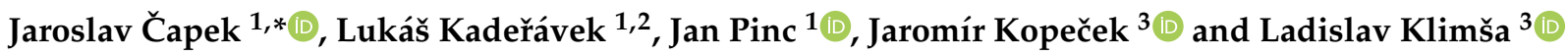 \\ 1 Department of Functional Materials, FZU-Institute of Physics of the Czech Academy of Sciences, \\ 18221 Prague, Czech Republic; kaderavek@fzu.cz (L.K.); pinc@fzu.cz (J.P.) \\ 2 Department of Materials, Faculty of Nuclear Sciences and Physical Engineering, Czech Technical University \\ in Prague, 11000 Prague, Czech Republic \\ 3 Department of Material Analysis, FZU-Institute of Physics of the Czech Academy of Sciences, \\ 18221 Prague, Czech Republic; kopecek@fzu.cz (J.K.); klimsa@fzu.cz (L.K.) \\ * Correspondence: capekj@fzu.cz; Tel.: +420-266-05-2604
}

Citation: Čapek, J.; Kadeřávek, L.; Pinc, J.; Kopeček, J.; Klimša, L.

Influence of the Microstructure of the Initial Material on the $\mathrm{Zn}$ Wires Prepared by Direct Extrusion with a Huge Extrusion Ratio. Metals 2021, 11, 787. https://doi.org/10.3390/ met11050787

Academic Editor: Andrey Belyakov

Received: 31 March 2021

Accepted: 9 May 2021

Published: 13 May 2021

Publisher's Note: MDPI stays neutral with regard to jurisdictional claims in published maps and institutional affiliations.

Copyright: () 2021 by the authors. Licensee MDPI, Basel, Switzerland. This article is an open access article distributed under the terms and conditions of the Creative Commons Attribution (CC BY) license (https:// creativecommons.org/licenses/by/ $4.0 /)$.
Abstract: In this study, we prepared zinc wires with a diameter of $250 \mu \mathrm{m}$ by direct extrusion using an extrusion ratio of 576 . We studied the influence of the extrusion temperature and microstructure of the initial $\mathrm{Zn}$ billets on the microstructural and mechanical characteristics of the extruded wires. The extrusion temperature played a significant role in the final grain size. The wires extruded at $300{ }^{\circ} \mathrm{C}$ possessed a coarse-grained microstructure and the shape of their tensile stress-strain curves suggested that twinning played an important role during their deformation. A significant influence of the initial grain size on the final microstructure was observed after the extrusion at $100{ }^{\circ} \mathrm{C}$. The wires prepared from the billet with a very coarse-grained microstructure possessed a bimodal grain size. A significant coarsening of their microstructure was observed after the tensile test. The wires prepared from the medium-grained billets at $100{ }^{\circ} \mathrm{C}$ were relatively coarse-grained, but their grain size was stable during the straining, resulting in the highest ultimate tensile strength. This preliminary study shows that strong attention should be paid to the extrusion parameters and the microstructure of the initial billets, because they significantly influence the microstructure and mechanical behavior of the obtained wires.

Keywords: Zn-based absorbable materials; biodegradable materials; extrusion; mechanical properties; microstructure

\section{Introduction}

Zinc and Zn-based materials have been extensively studied as absorbable materials for medical applications [1-5]. In contrast to the other two metals (Fe and $\mathrm{Mg}$ ) considered as absorbable materials, zinc and its alloys possess a more appropriate corrosion rate in the body environment [6,7]. Zinc possesses a low melting point $\left(\sim 420^{\circ} \mathrm{C}\right)$ and its casting can be performed in the air, which is a major benefit from an economical point of view.

The main drawback of zinc and its alloys is their poor strength ( $30 \mathrm{MPa}$, pure zinc) and ductility $(\sim 0.25 \%$, pure zinc) $[7,8]$ in the as-cast state. Cast zinc is usually coarsegrained; the increasing grain size decreases the critical resolved shear stress (CRSS) for twinning, which is the predominant deformation mechanism in coarse-grained Zn-based materials [9]. The extensive twinning leads to the twin-twin and twin-dislocation interactions, resulting in the formation of cracks and a subsequent decrease in ductility $[10,11]$. The mechanical performance can be enhanced by appropriate refinement of the microstructure. The medium-grained Zn-based materials deform mainly by dislocation slip, which results in an increase in both strength and ductility $[9,12]$. Another decrease in the grain-size can lead to a decrease in strength and increase in ductility due to the activation of the creep-like deformation mechanisms (dislocation climb, grain boundary sliding) $[9,13]$. The 
aforementioned suggests that a suitable adjustment of the grain size can alter the mechanical performance to be closer to the values desired for applications. Thermomechanical treatments, such as extrusion, rolling or equal channel angular pressing, are powerful tools for grain refinement [14]. The thermomechanical treatment is usually connected with the formation of a texture specific for a particular type of treatment. Because zinc is a metal with a hexagonal closed packed structure (HCP), its mechanical behavior strongly depends on the texture; therefore, the correct choice of the working method is necessary to achieve the desired mechanical properties [15-20]. Metallic absorbable materials are being considered for the fabrication of various osteosynthesis implants (nails, screws, splints, etc.), cardiovascular stents and sutures [21-23]. Stents and sutures are made of wires, which are usually fabricated by a cold drawing through a series of dies with decreasing cross-sections. Zinc is not malleable at room temperature; therefore, it has to be worked at elevated temperatures $\left(>100^{\circ} \mathrm{C}\right)$. At elevated temperatures, extrusion is a suitable method, because the mold can be easily tempered to the desired temperatures. Because metals are more malleable at elevated temperatures, the desired reduction of the diameter can be performed in one step, which may make the process more effective compared to the cold drawing.

In this paper, we will present our first study regarding the preparation and characterization of thin $\mathrm{Zn}$ wires ( $250 \mu \mathrm{m}$ in diameter) prepared by direct extrusion using a huge extrusion ratio of 576:1. The influence of the extrusion temperature and microstructure of the starting Zn blocks on the microstructure and mechanical properties of the extruded $\mathrm{Zn}$ wires will be discussed in the following sections.

\section{Materials and Methods}

\subsection{Initial Materials}

\subsubsection{Preparation Process}

Pure Zn rods (99.9999 wt.\%, Puratronic ${ }^{\circledR}$ ) were annealed to obtain two different microstructures. The annealing was performed in a Xerion electric resistance furnace (Xerion, Berlin, Germany) in an atmosphere of $99.999 \%$ argon gas at $400{ }^{\circ} \mathrm{C}$ for $72 \mathrm{~h}$ or at $100{ }^{\circ} \mathrm{C}$ for $1 \mathrm{~h}$. After the annealing, the materials were cooled in the furnace to ambient temperature.

\subsubsection{Microstructure}

The microstructure of the annealed rods (initial materials for the extrusion process) was observed using a light metallographic microscope Zeiss Axio Observer D1m (Carl Zeiss Microscopy GmbH, Jena, Germany). For this observation, metallographic cross-sections were prepared by electro-erosive cutting, subsequent grinding on $\mathrm{SiC}$ sandpapers and chemical polishing in a solution consisting of $100 \mathrm{~mL}$ of distilled water, $5 \mathrm{~mL}$ of nitric acid (65 wt.\%), $20 \mathrm{~g}$ of chromium (VI) oxide and $1.5 \mathrm{~g}$ of sodium sulphate. The microstructure was revealed by chemical etching in a mixture containing $1.5 \mathrm{~g}$ of sodium sulphate, $20 \mathrm{~g}$ of chromium (VI) oxide and $100 \mathrm{~mL}$ of distilled water.

The microstructure of the annealed rods will be shown and described in the Results section. The materials significantly differed in their grain size; therefore, they will be called coarse-grained (annealed at $400^{\circ} \mathrm{C}$ ) and medium-grained (annealed at $100^{\circ} \mathrm{C}$ ) $\mathrm{Zn}$.

\subsection{Extruded Wires}

\subsubsection{Preparation Process}

From the annealed rods, cylinders with a diameter of $5.95 \mathrm{~mm}$ and length of $20 \mathrm{~mm}$ were machined and extruded using a steel in-house-made extrusion mold with an extrusion ratio of 576. This extrusion ratio corresponds to the imposed true strain of 6.36 .

The imposed true strain can be calculated according to Equation (1) [24]:

$$
\varepsilon_{i m p}=\ln (E R),
$$


where $\varepsilon_{i m p}$ is the imposed true strain and $E R$ is the extrusion ratio (576).

The extrusion was performed at two different temperatures, namely $100{ }^{\circ} \mathrm{C}$ and $300{ }^{\circ} \mathrm{C}$. The extrusion mold was heated to the desired extrusion temperature using electricresistance elements. The extruded billets and the mold were carefully lubricated using a $\mathrm{MoS}_{2}$ high-temperature paste. The billets were placed into the extrusion mold (diameter of the billet container $6 \mathrm{~mm}$ ) and tempered at the extrusion temperature for $10 \mathrm{~min}$. Subsequently, the billets were passed through the channel with a diameter of $250 \mu \mathrm{m}$ using an in-house-built hydraulic press. The ram speed of $0.2 \mathrm{~mm} / \mathrm{s}$ was used. After the extrusion, the wires were wound up a spool with a diameter of $100 \mathrm{~mm}$. The designation of the $\mathrm{Zn}$ wires prepared from the initial materials with a different microstructure and at various extrusion temperatures is listed in Table 1. The designation mentioned in Table 1 will be used further in the text to enhance its lucidity, especially to abbreviate the labels and captions in figures and plots.

Table 1. Designation and preparation condition of the $\mathrm{Zn}$ wires studied in this manuscript.

\begin{tabular}{|c|c|c|}
\hline $\begin{array}{c}\text { Extrusion Temperature } \\
\text { X } \\
\text { Initial Material }\end{array}$ & $100^{\circ} \mathrm{C}$ & $300^{\circ} \mathrm{C}$ \\
\hline Medium-grained & MG_Ex $100^{\circ} \mathrm{C}$ & MG_Ex $300^{\circ} \mathrm{C}$ \\
\hline Coarse-grained & CG_Ex $100^{\circ} \mathrm{C}$ & CG_Ex $300^{\circ} \mathrm{C}$ \\
\hline
\end{tabular}

\subsubsection{Microstructure Characterization}

The surface of the wires was chemically polished in the same etching solution as was used for the initial material (Section 2.1.2). Subsequently, the microstructure was highlighted by chemical etching in a mixture containing $1.5 \mathrm{~g}$ of sodium sulphate, $20 \mathrm{~g}$ of chromium (VI) oxide and $100 \mathrm{~mL}$ of distilled water. After both chemical polishing and etching, the wires were rinsed with distilled water and ethanol.

The surfaces of the wires were documented using a FEI Phenom scanning electron microscope (SEM, ThermoFisher Scientific, Pfeddersheim, Germany). The average grain size was evaluated by the image analyses of the SEM micrographs of the etched wire surfaces. The ImageJ software (v.1.53e, Wayne Rasband and National Institutes of Health, MD, USA) was used for this purpose.

The cross- and longitudinal sections of the as-extruded wires and the cross-sections of the wires after mechanical testing were prepared by focused ion beam milling (FIB). The FIB milling was performed by a fully integrated Xe plasma source FIB using a scanning electron microscope (FIB-SEM) TESCAN FERA3 GM (TESCAN, Brno, Czech Republic). The process was monitored by secondary electron (SE) imaging (Everhart-Thornley SE detector) at $5 \mathrm{kV} / 120-260 \mathrm{pA}$. For both cross- and longitudinal section FIB milling of the $\mathrm{Zn}$ wires, FIB conditions of $30 \mathrm{kV} / 1 \mu \mathrm{A}$ were used for the initial rough milling of the material, followed by more precise polishing at $30 \mathrm{kV} / 300 \mathrm{nA}$, which was a sufficient surface treatment for observing electron backscattered diffraction (EBSD) patterns.

EBSD analyses were performed in the same FIB-SEM system using a versatile EDAX DigiView 5 high-resolution digital camera and electron beam at conditions of $30 \mathrm{kV} / 4.86 \mathrm{nA}$ with a $70^{\circ}$ sample pre-tilted stub holder at a working distance WD $=14 \mathrm{~mm}$. The MG Zn wires were analyzed with a $0.40 \mu \mathrm{m}$ step for both cross- and longitudinal section mapping, whereas the CG wires were analyzed with a $0.90 \mu \mathrm{m}$ step for cross-section and a $0.60 \mu \mathrm{m}$ step for longitudinal section mapping, respectively. From the EBSD data, the inverse pole figure (IPF) maps were evaluated using OIM 8 analysis software (EDAX, version 8, AMETEC, Inc., Montvale, NJ, USA). The IPF maps were evaluated for the plane perpendicular and parallel to the extrusion direction (ED and ND, respectively). 


\subsubsection{Characterization of the Mechanical Properties}

Mechanical behavior of the as-extruded wires was investigated from the point of view of a tensile test. First, while still on the spools, the wires were observed by the naked eye and a light microscope. This brief observation serves as the first preliminary check of the samples' shape, surface and other inhomogeneity, in order to avoid any premature failure given by some major defect of the specimen. For testing of the wire samples and definition of their gauge length for the proper setting of the tensile tests, stainless-steel capillaries were used. The samples were prepared from the spools in such a way that the samples' gauge lengths were defined by the crimping of these capillaries at both ends, thus preventing any further movement of the samples inside the capillaries. Therefore, the fully bored inner hole of the capillaries served as a guiding hole for the sample and simultaneously as the clamp, which was permanently enclosed by applying pressure from the outside by crimping pliers. Samples prepared in such way had, in all tests, a gauge length of $\sim 50 \mathrm{~mm}$. The samples were then mounted on an in-house-designed and -built universal thermomechanical testing rig for macroscopic observation. The rig consisted of a loading frame, sample environment chamber, electrically conductive grips with active water cooling, a load cell with $45 \mathrm{~N}$ tension and compression capacity and a linear actuator controlled with a position magnetic sensor with a precision class of $\pm 10 \mu \mathrm{m} / \mathrm{m}$. The used environment chamber enabled control of the temperature in the range of liquid nitrogen to $200^{\circ} \mathrm{C}$. With the original purpose of using the $\mathrm{Zn}$ wires as a biocompatible and biodegradable material, we chose the body temperature $\left(37^{\circ} \mathrm{C}\right)$ as the testing temperature for all experiments. The tests were carried out at constant strain rates of the moving crosshead of $1 \times 10^{-1} \% \cdot \mathrm{s}^{-1}$. The parameters of the tests were controlled and recorded via a National Instruments cRIO system and closed-loop LabVIEW control system.

\section{Results}

\subsection{Microstructure}

\subsubsection{Starting Materials}

The microstructure of the starting materials, i.e., the medium-grained (MG) and coarsegrained (CG) zinc annealed at $100^{\circ} \mathrm{C}$ for $1 \mathrm{~h}$ and at $400^{\circ} \mathrm{C}$ for $72 \mathrm{~h}$, respectively, is shown in Figure 1. The MG zinc consisted of relatively equiaxed grains with a size of up to $1 \mathrm{~mm}$. In contrast, the billets of the CG zinc were formed only by several grains with a size of several millimeters.

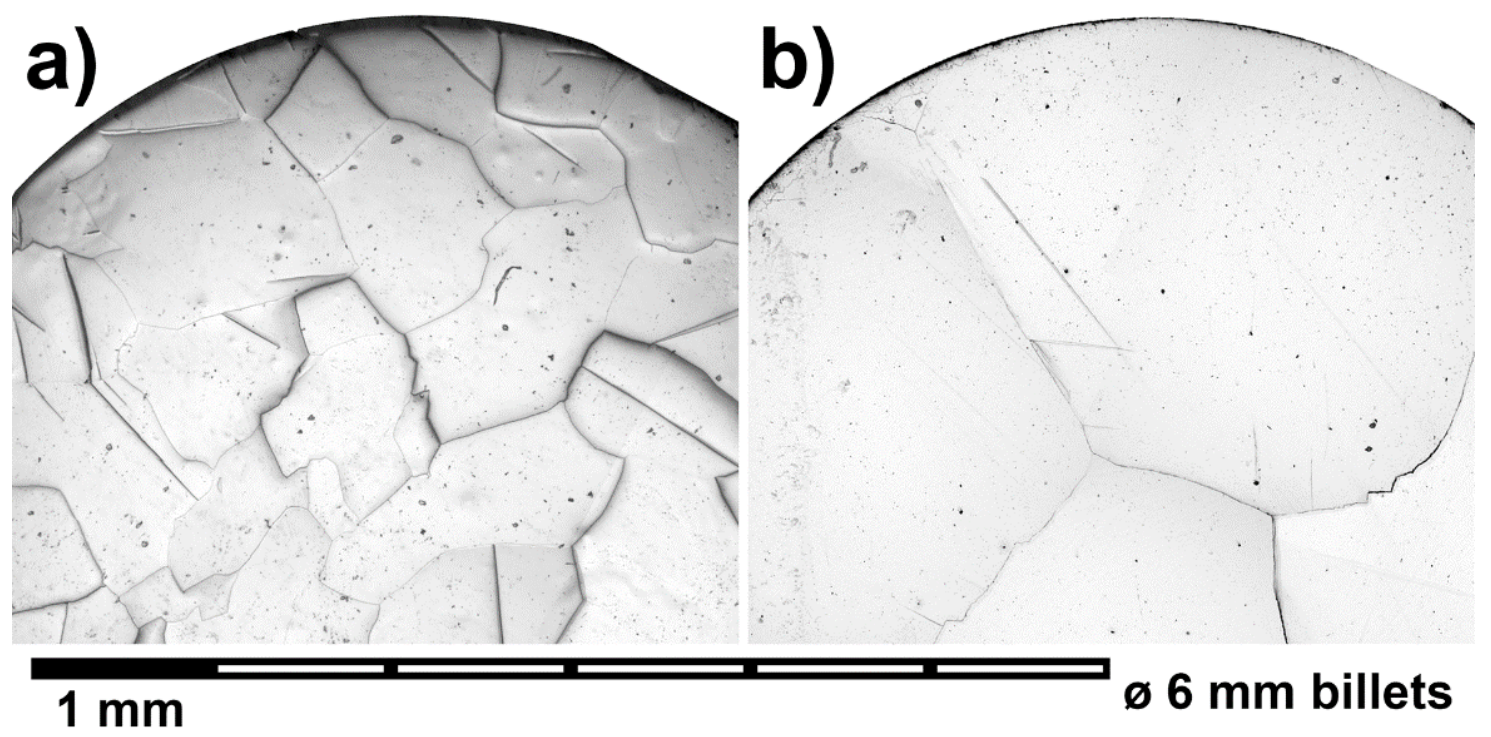

Figure 1. Stitched image showing microstructure of the extruded billets. (a) Medium-grained and (b) coarse-grained. 


\subsubsection{Extruded Zn Wires}

The SEM micrographs of the chemically polished and etched surfaces of the prepared $\mathrm{Zn}$ wires are shown in Figure 2. It is clearly visible in Figure 2 that the grains were of equiaxed shape and that the grain size on the surface increased with increasing extrusion temperature. An influence of the grain size of the initial billet on the grain size of the extruded wires was observed as well. At the higher extrusion temperature $\left(300^{\circ} \mathrm{C}\right)$, larger grain sizes were observed in the case of the CG wires, while the smallest grain size was observed in the case of the CG wire extruded at $100^{\circ} \mathrm{C}$. The average grain size obtained by the image analyses of the surface micrographs is listed in Table 2.
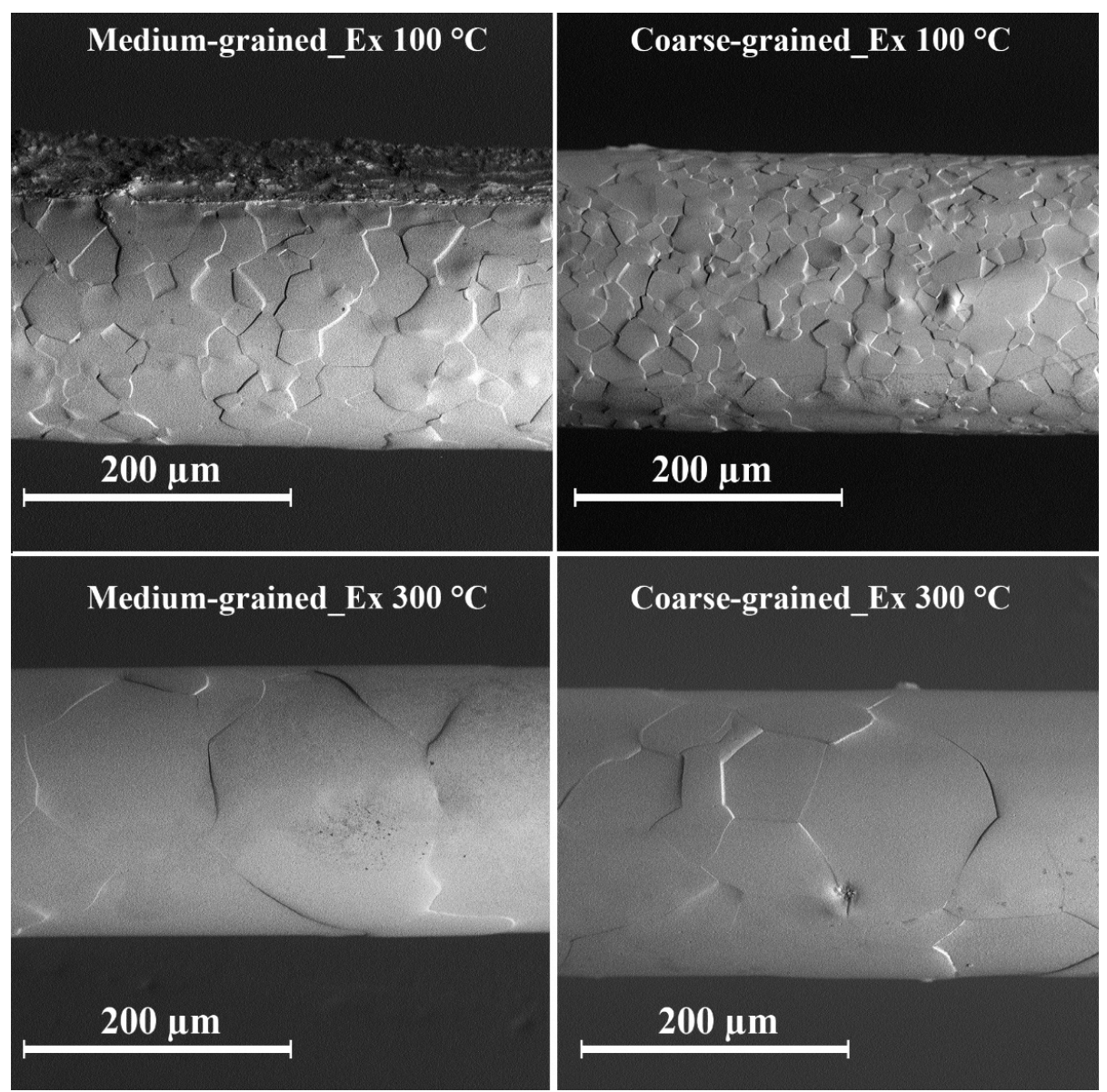

Figure 2. SEM micrographs of the chemically polished and etched $\mathrm{Zn}$ wires prepared at various conditions. Wires prepared by the extrusion of the medium-grained and coarse-grained zinc are shown in the left and right column, respectively. The extrusion temperature was $100{ }^{\circ} \mathrm{C}$ (1st row) and $300{ }^{\circ} \mathrm{C}$ (2nd row).

Table 2. Average grain size (in $\mu \mathrm{m}$ ) obtained by the image analyses of surface micrographs (Figure 2) and of the IPF maps (Figures 3-6).

\begin{tabular}{cccccc}
\hline Sample & $\begin{array}{c}\text { Surface } \\
\text { Micrographs } \\
\text { (Number } \\
\text { Fraction) }\end{array}$ & $\begin{array}{c}\text { IPF Maps } \\
\text { (Number } \\
\text { Fraction) } \\
\text { Cross-Section }\end{array}$ & $\begin{array}{c}\text { IPF Maps } \\
\text { (Area Fraction) } \\
\text { Cross-Section }\end{array}$ & $\begin{array}{c}\text { IPF Maps } \\
\text { (Number } \\
\text { Fraction) } \\
\text { Longitudinal } \\
\text { Section }\end{array}$ & $\begin{array}{c}\text { IPF Maps } \\
\text { (Area Fraction) } \\
\text { Longitudinal } \\
\text { Section }\end{array}$ \\
\hline MG_Ex 100 ${ }^{\circ} \mathrm{C}$ & $32 \pm 14$ & $43 \pm 26$ & $73 \pm 31$ & $74 \pm 26$ & $125 \pm 48$ \\
MG_Ex 300 ${ }^{\circ} \mathrm{C}$ & $230 \pm 98$ & $65 \pm 41$ & $113 \pm 55$ & $110 \pm 39$ & $127 \pm 37$ \\
CG_Ex 100 ${ }^{\circ} \mathrm{C}$ & $20 \pm 10$ & $16 \pm 10$ & $31 \pm 16$ & $17 \pm 11$ & $29 \pm 12$ \\
CG_Ex 300 ${ }^{\circ} \mathrm{C}$ & $267 \pm 113$ & $55 \pm 25$ & $73 \pm 21$ & $82 \pm 43$ & $121 \pm 45$ \\
\hline
\end{tabular}




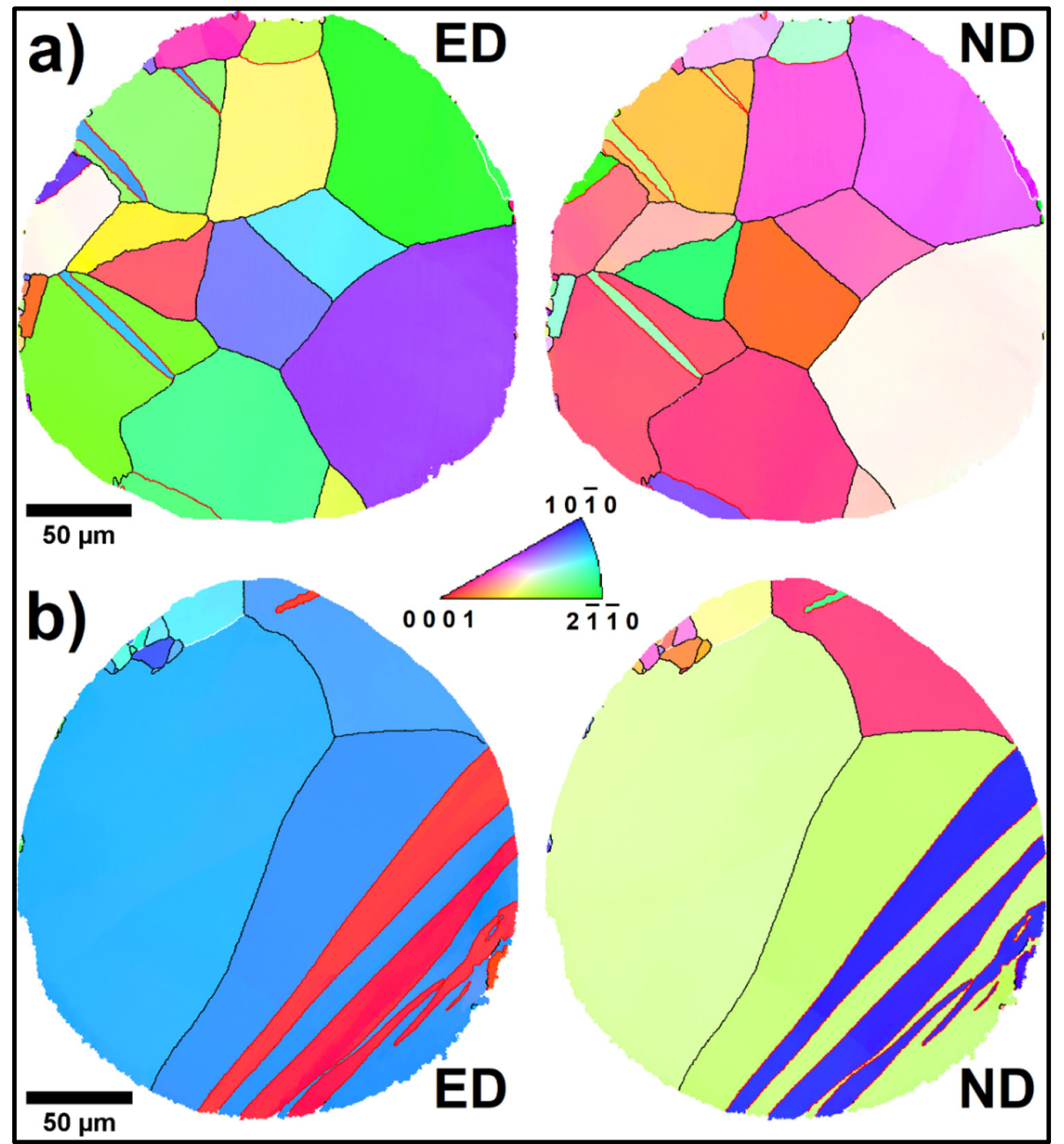

Figure 3. IPF maps of the cross-sections of the (a) MG_Ex $100{ }^{\circ} \mathrm{C}$ wire in ED and ND and (b) MG_Ex $300{ }^{\circ} \mathrm{C}$ wire in ED and ND. High angle boundaries $\left(>15^{\circ}\right)$ are highlighted in black, low angle boundaries $\left(5-15^{\circ}\right)$ in white and twin boundaries in red.

In order to investigate the microstructure of the wire cores, cross- and longitudinal sections were prepared and analyzed by EBSD. Because pure zinc is very sensitive to any mechanical deformation and it can recrystallize even at low temperatures, the crossand longitudinal sections were prepared by ion machining using Xe FIB. This prevented the recrystallization of the materials during sample preparation. The obtained inverse pole figure (IPF) maps are shown in Figures 3-6. In these figures, it is clearly visible that the increasing extrusion temperature resulted in a larger grain size. Although the wires extruded at $300{ }^{\circ} \mathrm{C}$ were very coarse-grained and the statistics for the determination of the texture were very poor, the obtained results suggest that an abnormal grain growth of grains with a certain orientation took place when the materials were extruded at $300{ }^{\circ} \mathrm{C}$. In the case of the CG_Ex $100^{\circ} \mathrm{C}$ wire, a bimodal grain size was observed and this material was of the finest microstructure. None of the material possessed the basal fiber texture, which is a common texture for as-extruded Zn-based materials [24,25]. We also observed an influence of the microstructure of the initial material on the microstructure of the extruded wires. In the case of the MG wires, twins were observed in the microstructure of the materials extruded at both temperatures. For the CG wires, the common feature was that the large grains were often subdivided by low-angle boundaries. 


\subsection{Mechanical Behavior of the $\mathrm{Zn}$ Wires}

The engineering tensile stress-strain curves of the prepared $\mathrm{Zn}$ wires are shown in Figure 7 and the values obtained from these curves are listed in Table 3. The tensile yield strengths (TYS) of all materials were very similar (39-46 MPa), but differences in the ultimate tensile strengths (UTS) were observed. The wires extruded at $300{ }^{\circ} \mathrm{C}$ reached lower UTS compared to their counterparts extruded at $100{ }^{\circ} \mathrm{C}$. The wires extruded at $300{ }^{\circ} \mathrm{C}$ possessed UTS of around $66 \mathrm{MPa}$. Relatively large variations in the obtained UTS and elongations to fracture were observed (see Table 3). This points out the higher inhomogeneity of the wires extruded at $300{ }^{\circ} \mathrm{C}$. The tensile stress-strain curves of these materials were serrated, suggesting that twinning took place during the deformation of these wires [26,27]. Regarding the wires extruded at $100{ }^{\circ} \mathrm{C}$, higher TYS was reached in the case of the MG_Ex $100^{\circ} \mathrm{C}$ wire; moreover, some serrations suggesting twinning were observed on the stress-strain tensile curves of the CG_Ex $100{ }^{\circ} \mathrm{C}$ wires.

\subsection{Ability to Be Knotted}

Because thin metallic wires are considered for the fabrication of absorbable sutures [21], it is important for the wires to be able to be knotted without any damage to the wire. In the case of the wires having serrated stress-strain curves, i.e., wires deformed by twinning, close tightening was impossible and the wires fractured. In the case of the MG_Ex $100{ }^{\circ} \mathrm{C}$ wire, we were able to tie the knot very tightly (see Figure 8).

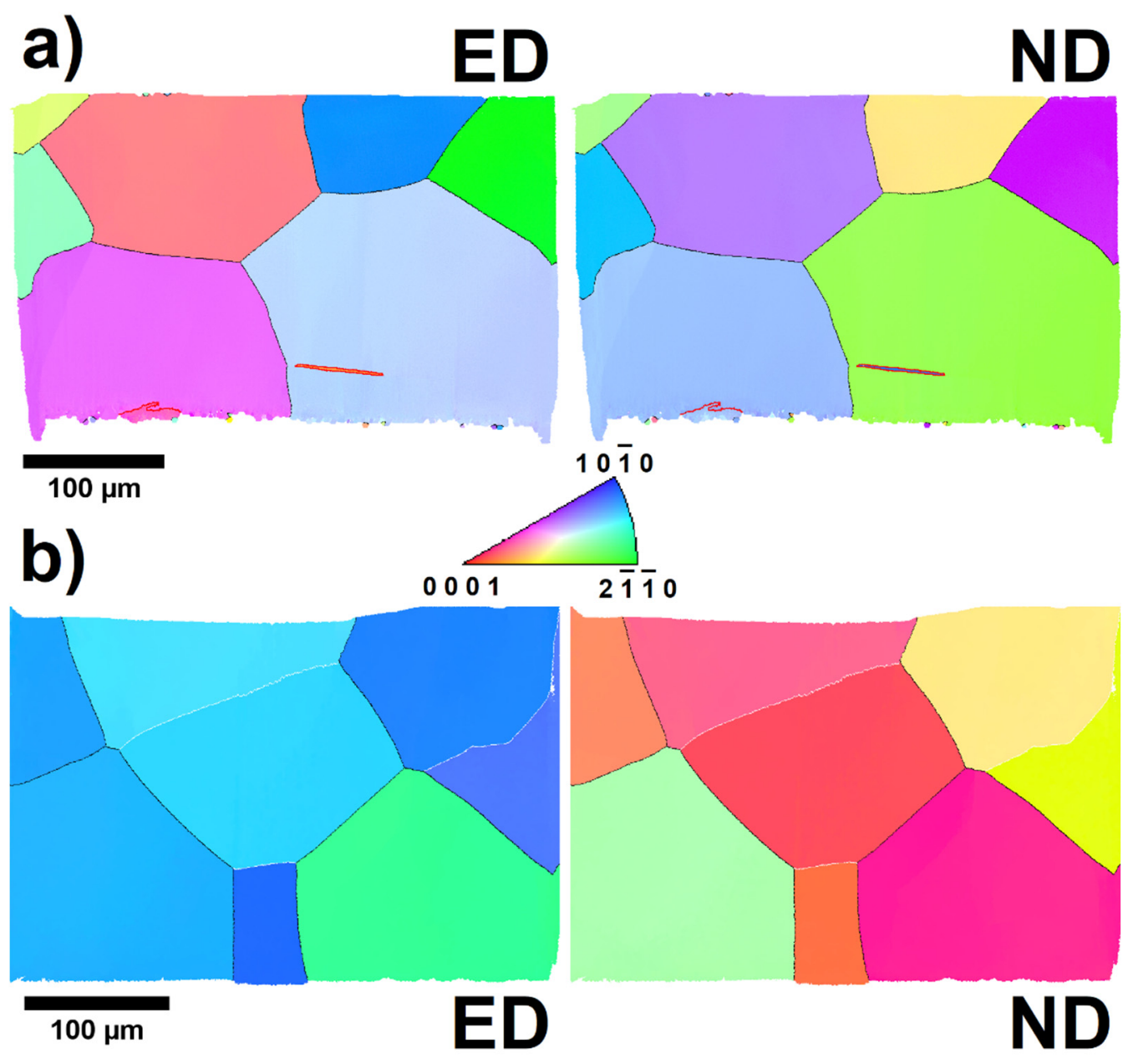

Figure 4. IPF maps of the longitudinal sections of the (a) MG_Ex $100{ }^{\circ} \mathrm{C}$ wire in ED and ND and (b) $\mathrm{MG}$ Ex $300{ }^{\circ} \mathrm{C}$ wire in ED and ND. High angle boundaries $\left(>15^{\circ}\right)$ are highlighted in black, low angle boundaries $\left(5-15^{\circ}\right)$ in white and twin boundaries in red. 


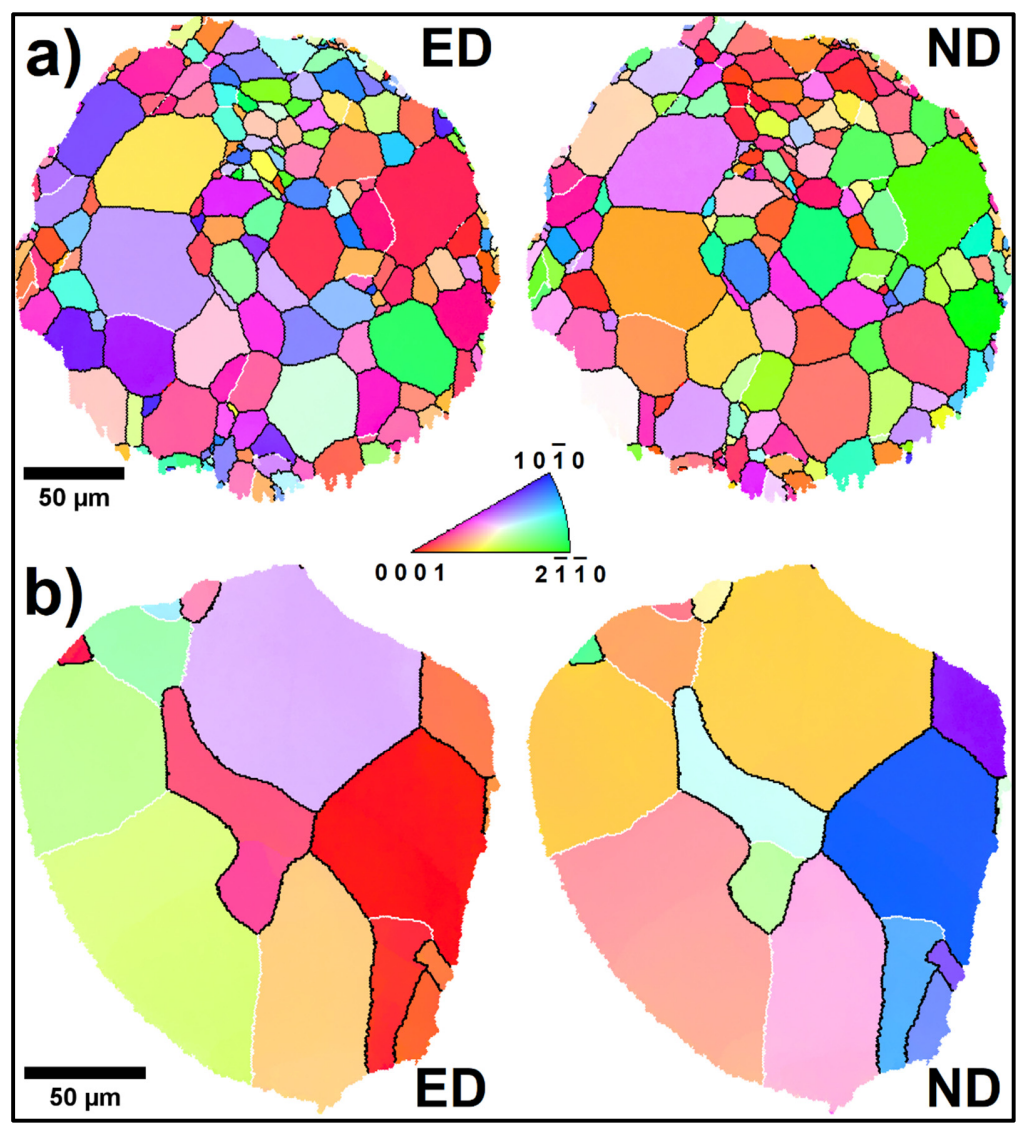

Figure 5. IPF maps of the cross-sections of the (a) CG_Ex $100{ }^{\circ} \mathrm{C}$ wire in ED and ND and (b) CG_Ex $300{ }^{\circ} \mathrm{C}$ wire in ED and ND. High angle boundaries $\left(>15^{\circ}\right)$ are highlighted in black and low angle boundaries $\left(5-15^{\circ}\right)$ in white.
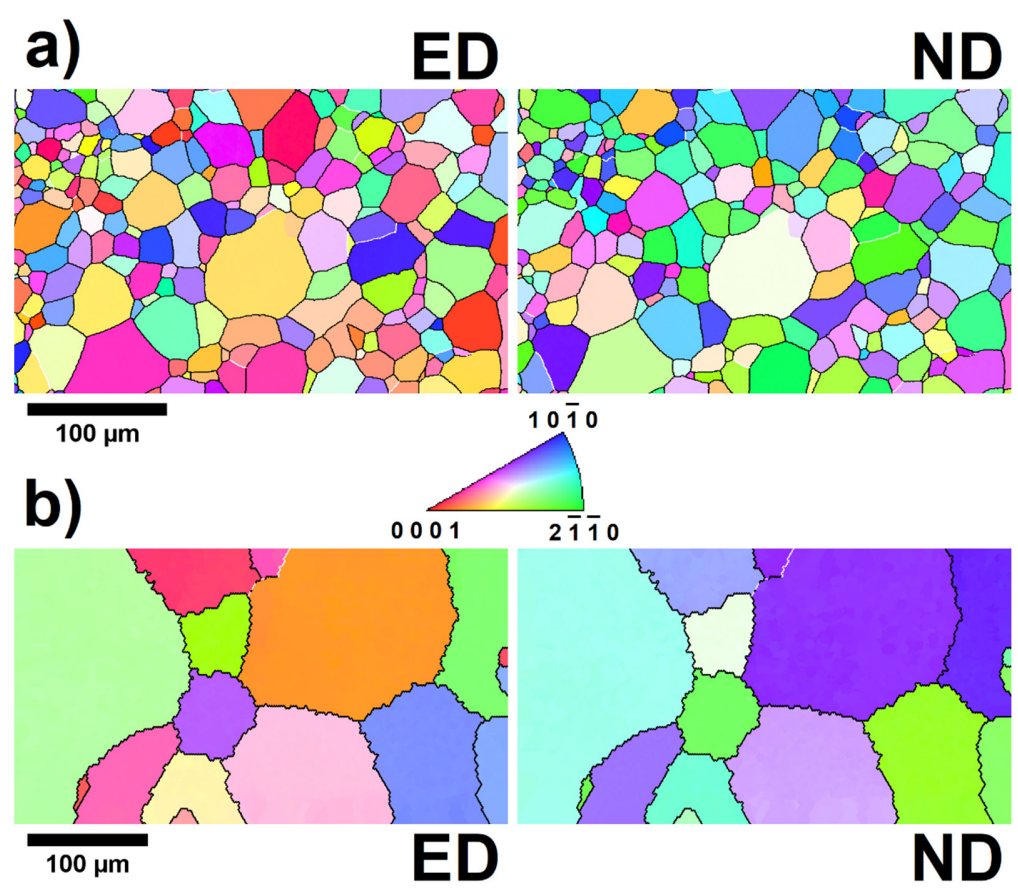

Figure 6. IPF maps of the longitudinal sections of the (a) CG_Ex $100{ }^{\circ} \mathrm{C}$ wire in ED and ND and (b) CG_Ex $300^{\circ} \mathrm{C}$ wire in ED and ND. High angle boundaries $\left(>15^{\circ}\right)$ are highlighted in black and low angle boundaries $\left(5-15^{\circ}\right)$ in white. 

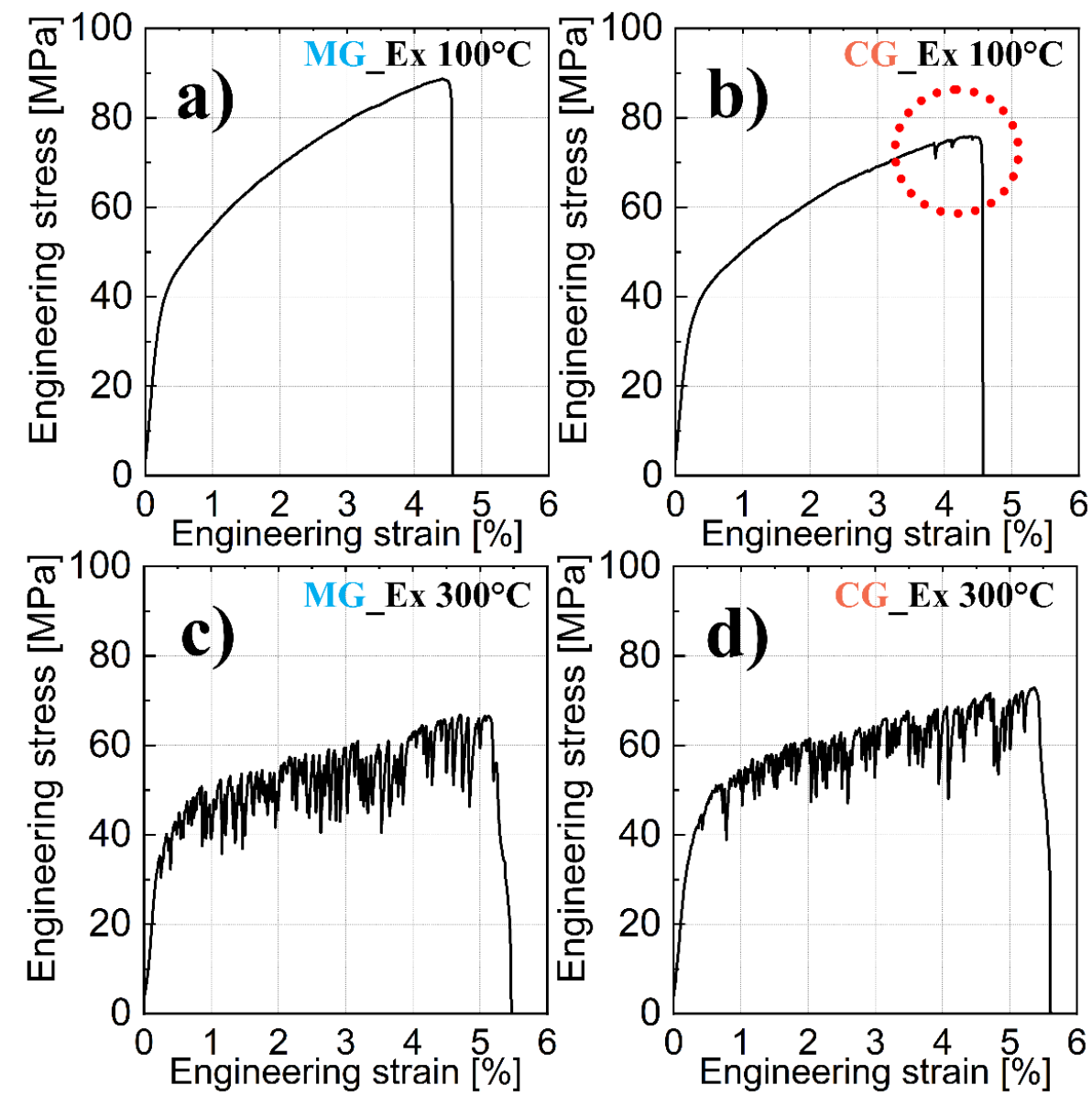

Figure 7. Tensile engineering stress-strain curves of the (a) MG_Ex $100{ }^{\circ} \mathrm{C}$, (b) CG_Ex $100{ }^{\circ} \mathrm{C}$, (c) MG_Ex $300^{\circ} \mathrm{C}$ and (d) CG_Ex $300^{\circ} \mathrm{C}$.

Table 3. Mechanical properties obtained from curves in Figure 7.

\begin{tabular}{cccc}
\hline Sample & $\begin{array}{c}\text { Tensile Yield Strength } \\
\mathbf{( M P a )}\end{array}$ & $\begin{array}{c}\text { Ultimate Tensile } \\
\text { Strength (MPa) }\end{array}$ & $\begin{array}{c}\text { Elongation to Fracture } \\
\mathbf{( \% )}\end{array}$ \\
\hline MG_Ex $100{ }^{\circ} \mathrm{C}$ & $45.7 \pm 2.7$ & $88.1 \pm 4.1$ & $4.6 \pm 0.9$ \\
\hline MG_Ex $300{ }^{\circ} \mathrm{C}$ & $38.7 \pm 2.2$ & $62.2 \pm 9.6$ & $4.3 \pm 2.1$ \\
\hline CG_Ex $100{ }^{\circ} \mathrm{C}$ & $40.6 \pm 1.6$ & $72.4 \pm 3.3$ & $4.4 \pm 0.3$ \\
\hline CG_Ex $300^{\circ} \mathrm{C}$ & $45.6 \pm 1.6$ & $69.3 \pm 10.2$ & $5.0 \pm 2.4$ \\
\hline
\end{tabular}

a)

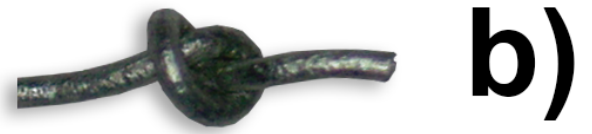

$2 \mathrm{~mm}$

Figure 8. Simple knots on selected wires: (a) MG_Ex $100{ }^{\circ} \mathrm{C}$ and (b) MG_Ex $300{ }^{\circ} \mathrm{C}$.

\section{Discussion}

As was clearly shown in Section 3.1, both extrusion temperature and initial microstructure can significantly influence the microstructure of the extruded wires. The increase in the grain size with increasing extrusion temperature was observed for both MG and CG initial $\mathrm{Zn}$ rods, and it can be simply explained by the decreasing Zener-Hollomon parameter, which decreases exponentially with the increasing extrusion temperature [24]. As is visible 
in Table 2, the grain size obtained from the SEM micrographs of the etched surfaces and from the EBSD data significantly differed. This can be explained in the following way: (i) the chemical etching does not highlight low angle boundaries and is not suitable for the distinguishing of neighboring grains with similar orientation. The wires extruded at $300{ }^{\circ} \mathrm{C}$ were strongly textured. Moreover, the CG_Ex $300{ }^{\circ} \mathrm{C}$ contained numerous low angle boundaries; therefore, the significantly larger grain size was observed on the surface of the wires extruded at $300{ }^{\circ} \mathrm{C}$. (ii) The grain size on the surface should not necessarily reflect the grain size in the core of the wire. In our opinion, the grain size obtained from the EBSD data is more reliable and, based on them, we can conclude that CG wires possessed finer microstructures than the MG wires extruded at the same temperature. Moreover, the texture of the MG and CG wires differed. There could be several reasons for the influence of the initial grain size. (i) The initial grain size can influence the deformation mechanisms taking place during the extrusion. Coarse-grained materials are more sensitive to twinning or the formation of shear bands. Such microstructural defects can act as initiation sites for recrystallization and the formation of fine-grained bands, and chains can be expected in coarse-grained materials deformed at elevated temperatures [9,14,28-30]. On the other hand, more intensive and homogeneous dynamic recrystallization is usually observed in the case of materials with finer microstructures. This is because a larger number of grain boundaries are present in fine-grained materials, and the grain boundaries act as nucleation sites for recrystallization. As a result, the newly recrystallized grain size is more homogeneous [14,30]. (ii) The CG billets were obtained by annealing at a large homologous temperature ( 0.97 of the melting point) for a long time period. This might lead to preferential grain growth. As a consequence, coarse grains with similar crystallographic orientation could occur in the CG material [31,32]. As a result, some deformation mechanisms could be prohibited in the CG zinc, and different recrystallization mechanisms could take place during the extrusion of the MG and CG Zn billets as a consequence. This subsequently results in differences in the grain size and texture of the wires.

The differences in the microstructure led to differences in the deformation behavior of the wires. The wires extruded at $300{ }^{\circ} \mathrm{C}$ tended to twin during the deformation, which is suggested by the serrated tensile stress-strain curves [26,27]. It is necessary to mention that the serrations could be observed also due to other effects, particularly due to the Portevin-Le Chaterilier effect [33] or due to the formation of cleavage cracks [34]. In our case, these effects can be excluded. The Portevin-Le Chaterilier effect takes place only for alloys, not for pure metals [33]. The formation of cleavage cracks would lead to a decrease in ductility compared to the materials which were deformed without the formation of cleavage cracks (MG_Ex $100{ }^{\circ} \mathrm{C}$ and CG_Ex $100{ }^{\circ} \mathrm{C}$ ), but we observed comparable ductility for all wires. This makes the connection between the formation of cleavage cracks and the serration on the tensile curves improbable. The tendency towards twinning can be explained by the large grain size, which decreases the critical resolved shear stress (CRSS) for twinning $[9,28]$. Interesting findings were collected in the case of the wires extruded at $100{ }^{\circ} \mathrm{C}$. Higher TYS and UTS were observed for the MG_Ex $100{ }^{\circ} \mathrm{C}$, even though this wire possessed a significantly coarser microstructure than the CG_Ex $100{ }^{\circ} \mathrm{C}$. The differences in TYS can be explained by the differences in texture and consequently by the differences in the Schmid factor for the basal slip (the predominant deformation mechanism in zinc [35]). The maps of the Schmid factor for the basal slip are shown in Figure 9. In the CG_Ex $100{ }^{\circ} \mathrm{C}$, the majority of grains possessed a large Schmid factor for basal slip, while a large portion of grains in the MG_Ex $100{ }^{\circ} \mathrm{C}$ had a lower Schmid factor for the basal slip. This means that higher external stress was necessary to plastically deform the MG_Ex $100{ }^{\circ} \mathrm{C}$ wire. Moreover, the fine grains in the CG_Ex $100{ }^{\circ} \mathrm{C}$ can promote the non-slip deformation mechanisms, such as grain boundary sliding $[9,13]$. 


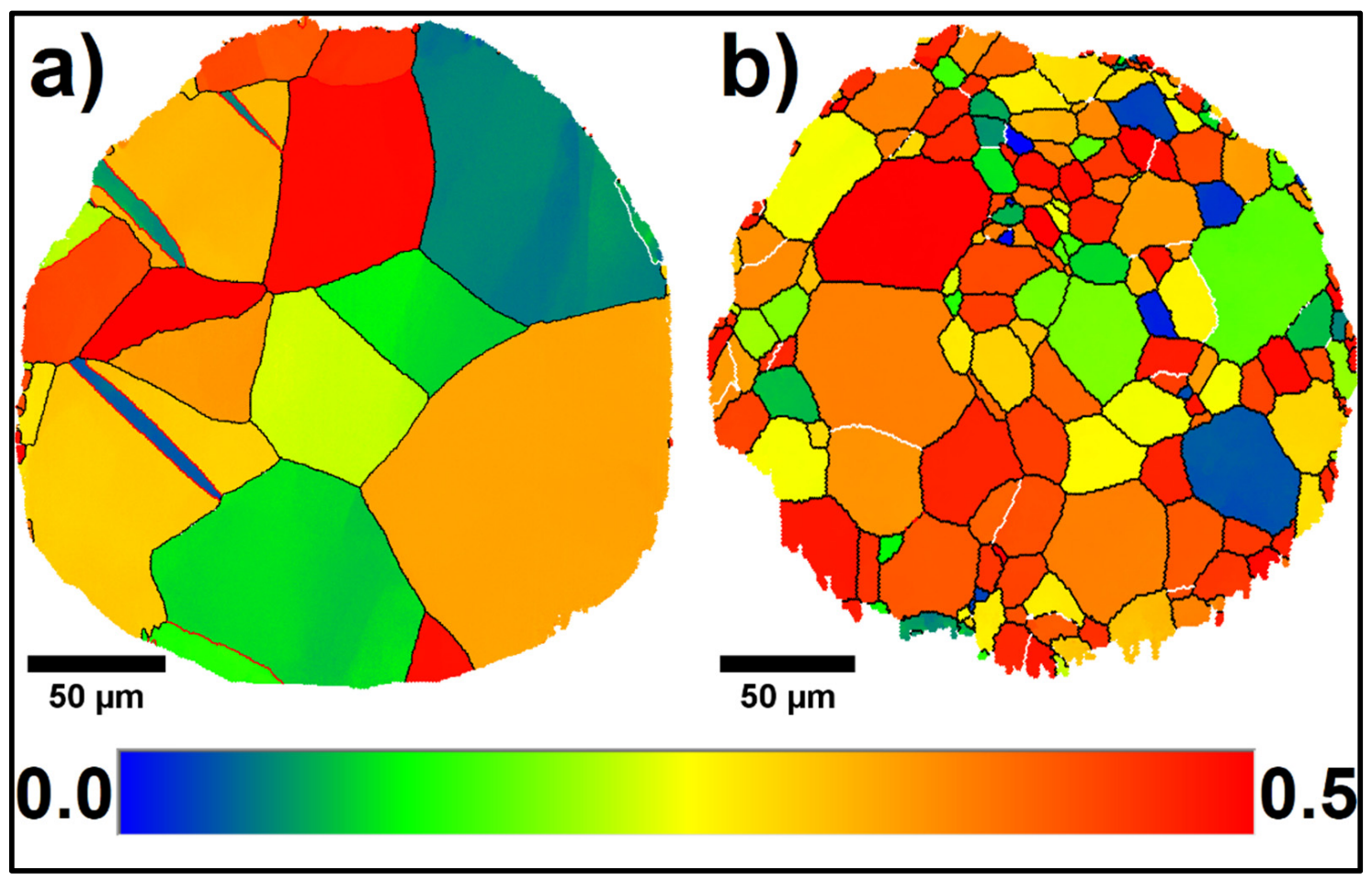

Figure 9. Schmid factor maps of the (a) MG_Ex $100{ }^{\circ} \mathrm{C}$ and (b) CG_Ex $100^{\circ} \mathrm{C}$ wires.

In addition, serrations suggesting twinning were observed on the stress-strain curves of the CG_Ex $100{ }^{\circ} \mathrm{C}$ wires, which was very surprising because of the small grain size of this wire. Therefore, we performed an FIB cut near the fracture surface of the wires extruded at $100{ }^{\circ} \mathrm{C}$ after the tensile tests. The IPF and Schmid factor maps of these cuts are shown in Figure 10. Figure 10 clearly shows that strong grain coarsening took place during the deformation of the CG_Ex $100{ }^{\circ} \mathrm{C}$ wire. This was caused by a stress-strain-assisted grain growth. It could be attributed to the bimodal grain size of the CG_Ex $100{ }^{\circ} \mathrm{C}$ wire. It can be expected that the larger grains grew at the expense of the fine grains. As is shown in Figure 10d, a large portion of the overgrown grains possessed low values of Schmid factor for the basal slip. As a consequence of the combination of the large grain size and low value of Schmid factor, twinning possibly took place in the late stages of the deformation of the CG_Ex $100{ }^{\circ} \mathrm{C}$ wires (encircled area in Figure $7 \mathrm{~b}$ ). It should be also mentioned that only several grains were distributed over the diameter of the wires. This means that the wires could be considered as oligocrystals. This could explain why the wires reached slightly lower values of tensile strength and ductility compared to the pure extruded zinc studied in other works $[13,36]$ — the so-called size effect $[37,38]$. It should be mentioned that the differences between the mechanical performance of the $\mathrm{Zn}$ wires and bulk samples could be also caused by the differences in grain size and texture. The microstructural stability and the absence of twinning in the case of the MG_Ex $100{ }^{\circ} \mathrm{C}$ led to it displaying the best ability to be knotted. This is a very important property for its application as sutures on soft tissue or sutures used in sternum surgery [21]. We are aware that the strength of the prepared wires can be low and insufficient for surgical application. However, suitable alloying-for example, with magnesium-should allow significantly higher strengths to be achieved [39]. In general, suitable alloying leads to pinning of the grain boundaries and the achievement finer grain sizes after the extrusion. It should result in an increase in strength and ductility [13]. The design of malleable Zn-based alloys possessing high strength is the aim of our ongoing study. 


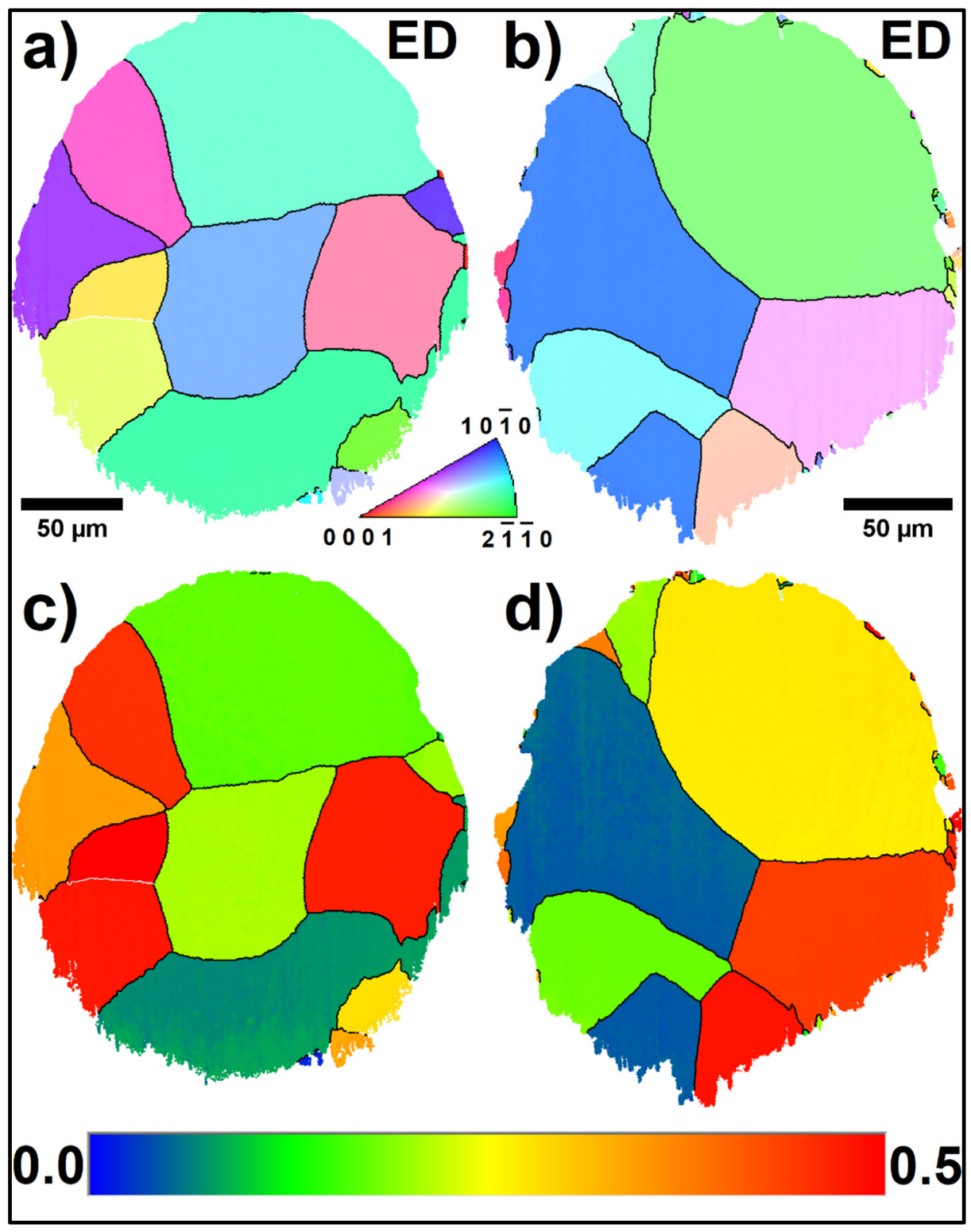

Figure 10. IPF maps in ED belonging to (a) MG_Ex $100^{\circ} \mathrm{C}$ and (b) CG_Ex $100{ }^{\circ} \mathrm{C}$ and maps of Schmid factor for basal slip corresponding to (c) MG_Ex $100{ }^{\circ} \mathrm{C}$ and (d) $\mathrm{CG} \_\mathrm{Ex} 100{ }^{\circ} \mathrm{C}$.

\section{Conclusions}

In this work, we successfully prepared $\mathrm{Zn}$ wires by direct extrusion with an extremely huge extrusion ratio of 576:1. Based on the obtained results, several main conclusions can be drawn:

i. $\quad$ The extrusion process led to the preparation of wires whose texture did not correspond to the basal fiber texture, which is common for extruded Zn-based materials.

ii. $\quad$ An increase in the extrusion temperature resulted in an increase in grain size.

iii. The microstructure of the initial $\mathrm{Zn}$ billets strongly influenced the microstructure of the wires extruded at $100{ }^{\circ} \mathrm{C}$.

iv. The as-extruded CG_Ex $100{ }^{\circ} \mathrm{C}$ possessed a bimodal grain size. This resulted in the stress-strain-assisted grain growth during the tensile test and a subsequent decrease in the ultimate tensile strength.

v. The obtained results suggest that the direct extrusion could be an effective method for the fabrication of $\mathrm{Zn}$-based wires intended for surgical suture applications. 
However, fine control of the final grain size and strengthening of zinc by alloying will be most likely necessary.

Author Contributions: Conceptualization, Investigation, Project administration, Writing-original draft, Writing—review and editing, Supervision, J.C..; Investigation, Writing—review and editing, J.P. Investigation, Writing—review and editing, L.K. (Lukáš Kadeřávek); Investigation, Writing-review and editing, J.K.; Investigation, Writing—review and editing, L.K. (Ladislav Klimša). All authors have read and agreed to the published version of the manuscript.

Funding: This research was funded by the Czech Science Foundation, grant number 18-06110S, Operational Program Research, Development and Education financed by European Structural and Investment Funds and the Czech Ministry of Education, Youth and Sports (Project No. SOLID21CZ.02.1.01/0.0/0.0/16_019/0000760) and by the CzechNanoLab Research Infrastructure supported by MEYS CR (LM2018110).

Institutional Review Board Statement: Not applicable.

Informed Consent Statement: Not applicable.

Data Availability Statement: The raw/processed data will be provided on request.

Acknowledgments: We would like to acknowledge to Stanislav Habr for the preparation of the $\mathrm{Zn}$ wires by the extrusion process.

Conflicts of Interest: The authors declare no conflict of interest.

\section{References}

1. Yang, H.; Jia, B.; Zhang, Z.; Qu, X.; Li, G.; Lin, W.; Zhu, D.; Dai, K.; Zheng, Y. Alloying design of biodegradable zinc as promising bone implants for load-bearing applications. Nat. Commun. 2020, 11, 401. [CrossRef] [PubMed]

2. Shi, Z.-Z.; Gao, X.-X.; Zhang, H.-J.; Liu, X.-F.; Li, H.-Y.; Zhou, C.; Yin, Y.-X.; Wang, L.-N. Design biodegradable Zn alloys: Second phases and their significant influences on alloy properties. Bioact. Mater. 2020, 5, 210-218. [CrossRef] [PubMed]

3. Su, Y.; Cockerill, I.; Wang, Y.; Qin, Y.-X.; Chang, L.; Zheng, Y.; Zhu, D. Zinc-Based Biomaterials for Regeneration and Therapy. Trends Biotechnol. 2019, 37, 428-441. [CrossRef] [PubMed]

4. Champagne, S.; Mostaed, E.; Safizadeh, F; Ghali, E.; Vedani, M.; Hermawan, H. In vitro degradation of absorbable zinc alloys in artificial urine. Materials 2019, 12, 295. [CrossRef] [PubMed]

5. Hernández-Escobar, D.; Champagne, S.; Yilmazer, H.; Dikici, B.; Boehlert, C.J.; Hermawan, H. Current status and perspectives of zinc-based absorbable alloys for biomedical applications. Acta Biomater. 2019, 97, 1-22. [CrossRef]

6. Bowen, P.K.; Drelich, J.; Goldman, J. Zinc Exhibits Ideal Physiological Corrosion Behavior for Bioabsorbable Stents. Adv. Mater. 2013, 25, 2577-2582. [CrossRef]

7. Levy, G.K.; Goldman, J.; Aghion, E. The Prospects of Zinc as a Structural Material for Biodegradable Implants—A Review Paper. Metals 2017, 7, 402. [CrossRef]

8. Li, H.F.; Xie, X.H.; Zheng, Y.F.; Cong, Y.; Zhou, F.Y.; Qiu, K.J.; Wang, X.; Chen, S.H.; Huang, L.; Tian, L.; et al. Development of biodegradable Zn-1X binary alloys with nutrient alloying elements Mg, Ca and Sr. Sci. Rep. 2015, 5, 10719. [CrossRef]

9. Chmelík, F.; Trojanová, Z.; Lukáč, P.; Převorovský, Z. Acoustic emission from zinc deformed at room temperature Part II The influence of grain size on deformation behaviour and acoustic emission of pure zinc. J. Mater. Sci. Lett. 1993, 12, 1166-1168. [CrossRef]

10. Yoo, M.H. Slip, twinning, and fracture in hexagonal close-packed metals. Metall. Trans. A 1981, 12, 409-418. [CrossRef]

11. Paidar, V.; Capek, J. Anisotropy of fracture in hexagonal metals. Int. J. Fract. 2020, 225, 123-127. [CrossRef]

12. Ratnaji Rao, K.; Ranganathan, S.; Sastry, D.H. Effect of texture and grain size on the mechanical properties of warm-worked cadmium, zinc and zinc-0.35\% aluminium alloy. Bull. Mater. Sci. 1986, 8, 81-89. [CrossRef]

13. Bednarczyk, W.; Watroba, M.; Kawałko, J.; Bała, P. Can zinc alloys be strengthened by grain refinement? A critical evaluation of the processing of low-alloyed binary zinc alloys using ECAP. Mater. Sci. Eng. A 2019, 748, 357-366. [CrossRef]

14. Sakai, T.; Belyakov, A.; Kaibyshev, R.; Miura, H.; Jonas, J.J. Dynamic and post-dynamic recrystallization under hot, cold and severe plastic deformation conditions. Prog. Mater. Sci. 2014, 60, 130-207. [CrossRef]

15. Paidar, V.; Čapek, J. Anisotropy of Plastic Deformation in Hexagonal Metals. Mater. Sci. Forum 2021, 1016, 1091-1096. [CrossRef]

16. Desmond, T. Elastic anisotropy of hcp metal crystals and polycrystals. Int. J. Res. Rev. Appl. Sci. 2011, 6, 462-483.

17. Beyerlein, I.J.; Tóth, L.S. Texture evolution in equal-channel angular extrusion. Prog. Mater. Sci. 2009, 54, 427-510. [CrossRef]

18. Suwas, S.; Mondal, S. Texture Evolution in Severe Plastic Deformation Processes. Mater. Trans. 2019, 60, 1457-1471. [CrossRef]

19. $\mathrm{Hu}, \mathrm{H}$. Texture of Metals. Texture 1974, 1, 233-258. [CrossRef]

20. Wang, Y.N.; Huang, J.C. Texture analysis in hexagonal materials. Mater. Chem. Phys. 2003, 81, 11-26. [CrossRef]

21. Seitz, J.-M.; Durisin, M.; Goldman, J.; Drelich, J.W. Recent Advances in Biodegradable Metals for Medical Sutures: A Critical Review. Adv. Healthc. Mater. 2015, 4, 1915-1936. [CrossRef] 
22. Zheng, Y.F.; Gu, X.N.; Witte, F. Biodegradable metals. Mater. Sci. Eng. R Rep. 2014, 77, 1-34. [CrossRef]

23. Moravej, M.; Mantovani, D. Biodegradable metals for cardiovascular stent application: Interests and new opportunities. Int. J. Mol. Sci. 2011, 12, 4250-4270. [CrossRef]

24. Capek, J.; Kubasek, J.; Pinc, J.; Drahokoupil, J.; Cavojsky, M.; Vojtech, D. Extrusion of the biodegradable ZnMg0.8Ca0.2 alloy-The influence of extrusion parameters on microstructure and mechanical characteristics. J. Mech. Behav. Biomed. Mater. 2020, 108, 103796. [CrossRef]

25. Capek, J.; Kubasek, J.; Pinc, J.; Manak, J.; Molnarova, O.; Drahokoupil, J.; Cavojsky, M. ZnMg0.8Ca0.2 (wt\%) biodegradable alloy-The influence of thermal treatment and extrusion on microstructural and mechanical characteristics. Mater. Charact. 2020, 162, 110230. [CrossRef]

26. Lentz, M.; Risse, M.; Schaefer, N.; Reimers, W.; Beyerlein, I.J. Strength and ductility with $\{10 T 1\}-\{10 T 2\}$ double twinning in a magnesium alloy. Nat. Commun. 2016, 7, 11068. [CrossRef]

27. Della Ventura, N.M.; Kalácska, S.; Casari, D.; Edwards, T.E.J.; Sharma, A.; Michler, J.; Logé, R.; Maeder, X. $\left\{101^{-} 2\right\}$ twinning mechanism during in situ micro-tensile loading of pure Mg: Role of basal slip and twin-twin interactions. Mater. Des. 2021, 197, 109206. [CrossRef]

28. Ecob, N.; Ralph, B. The effect of grain size on deformation twinning in a textured zinc alloy. J. Mater. Sci. 1983, 18, 2419-2429. [CrossRef]

29. Guan, D.; Rainforth, W.M.; Ma, L.; Wynne, B.; Gao, J. Twin recrystallization mechanisms and exceptional contribution to texture evolution during annealing in a magnesium alloy. Acta Mater. 2017, 126, 132-144. [CrossRef]

30. Huang, K.; Logé, R.E. A review of dynamic recrystallization phenomena in metallic materials. Mater. Des. 2016, 111, 548-574. [CrossRef]

31. Pérez-Prado, M.T.; Ruano, O.A. Texture evolution during annealing of magnesium AZ31 alloy. Scr. Mater. 2002, 46, 149-155. [CrossRef]

32. Sahoo, S.K.; Sabat, R.K.; Panda, S.; Mishra, S.C.; Suwas, S. Texture and microstructure evolution of pure zinc during rolling at liquid nitrogen temperature and subsequent annealing. Mater. Charact. 2017, 123, 218-226. [CrossRef]

33. Yilmaz, A. The Portevin-Le Chatelier effect: A review of experimental findings. Sci. Technol. Adv. Mater. 2011, $12,063001$. [CrossRef]

34. Liu, J.H.; Huang, C.X.; Wu, S.D.; Zhang, Z.F. Tensile deformation and fracture behaviors of high purity polycrystalline zinc. Mater. Sci. Eng. A 2008, 490, 117-125. [CrossRef]

35. Liu, S.; Kent, D.; Zhan, H.; Doan, N.; Dargusch, M.; Wang, G. Dynamic recrystallization of pure zinc during high strain-rate compression at ambient temperature. Mater. Sci. Eng. A 2020, 784, 139325. [CrossRef]

36. Čapek, J.; Kubásek, J.; Pinc, J.; Fojt, J.; Krajewski, S.; Rupp, F.; Li, P. Microstructural, mechanical, in vitro corrosion and biological characterization of an extruded Zn-0.8Mg-0.2Sr (wt\%) as an absorbable material. Mater. Sci. Eng. C 2021, 122, 111924. [CrossRef]

37. Murphy, B.P.; Savage, P.; McHugh, P.E.; Quinn, D.F. The Stress-Strain Behavior of Coronary Stent Struts is Size Dependent. Ann. Biomed. Eng. 2003, 31, 686-691. [CrossRef]

38. Mitevski, B.; Weiß, S. Fatigue of Thin, Oligo-Crystalline Wires Made of X2 CrNiMo 18-15-3. Metals 2018, 8, 333. [CrossRef]

39. Okamura, Y.; Hinata, N.; Hoshiba, T.; Nakatsuji, T.; Ikeo, N.; Furukawa, J.; Harada, K.; Nakano, Y.; Fukumoto, T.; Mukai, T.; et al. Development of bioabsorbable zinc-magnesium alloy wire and validation of its application to urinary tract surgeries. World $J$. Urol. 2021, 39, 201-208. [CrossRef] 